\title{
Octogenarians with Multiple Sclerosis: Lessons for Aging in Place
}

\author{
Matthew B. Downer, ' Elizabeth M. Wallack, 'Michelle Ploughman, ' and the Health, Lifestyle, \\ and Aging with MS Canadian Consortium²
}

\begin{abstract}
RÉSUMÉ
Les facteurs de protection retrouvés chez des octogénaires atteints de sclérose en plaques (SP) vivant à domicile ont été comparés à ceux d'individus sans SP du même groupe d'âge et de personnes moins âgées atteintes de SP. Les données provenant des octogénaires atteints de SP $(n=23)$ et d'un groupe de répondants plus jeunes avec cette maladie $(n=61)$ ont été tirées d'une enquête canadienne sur le vieillissement avec SP. Les données des groupes avec SP ont été comparées aux statistiques nationales d'octogénaires de la population générale. Les octogénaires avec SP présentaient plus d'incapacités et une prévalence plus élevée de troubles de l'humeur, mais étaient physiquement plus actifs que la population d'octogénaires de l'enquête canadienne. Les octogénaires avec SP ont déclaré éprouver moins de stress et de fatigue que le groupe d'individus plus jeunes avec SP. Bien que la différence d'âge entre les deux groupes avec SP soit d'une dizaine d'années, ces groupes ont rapporté des niveaux similaires de soutien social, d'aisance financière, d'incapacité physique et de participation. Le maintien d'appuis solides (sociaux et financiers), d'une attitude positive, la pratique d'activité physique et la participation aux activités quotidiennes peuvent contribuer au vieillissement dans la collectivité chez les individus avec SP, malgré les défis amenés par cette maladie.
\end{abstract}

\begin{abstract}
We aimed to determine protective factors distinguishing octogenarians with multiple sclerosis (MS) living at home from others their age and younger people with MS. Data from MS octogenarians $(n=23)$ and a matched group of MS youngold respondents $(n=61)$ were extracted from a Canadian MS aging survey. The MS groups were compared, along with a group of octogenarians from the general population, using national statistics. MS octogenarians lived with greater disability and higher prevalence of mood disorders but were more physically active than Canadian octogenarians without MS. MS octogenarians reported less stress and fatigue than the MS young-old group, and despite being more than a decade older, they reported similar levels of social support, financial flexibility, physical disability, and participation. Even when challenged by MS, maintenance of strong supports (social and financial), positive attitude, and participation in physical activity and life roles may contribute to aging in place.
\end{abstract}

1 Recovery \& Performance Laboratory, Faculty of Medicine, Memorial University, St. John's, Newfoundland and Labrador

2 Health, Lifestyle, and Aging with MS Canadian Consortium, St. John's, Newfoundland and Labrador*

* Members of the Health, Lifestyle, and Aging with MS Canadian Consortium are John D. Fisk, Ph.D., Nancy Mayo, Ph.D., A. Dessa Sadovnick, Ph.D., Serge Beaulieu, B.Sc., Paul O'Connor, M.D., F.R.C.P.C., Sarah A. Morrow, M.D., F.R.C.P.C., Katherine B. Knox, M.D., F.R.C.P.C., Luanne M. Metz, M.D., F.R.C.P.C., Penelope Smyth, M.D., F.R.C.P.C., Ruth Ann Marrie, M.D., Ph.D., Mark Stefanelli, M.D. F.R.C.P.C., and Marshall Godwin, M.D.

Manuscript received: / manuscrit reçu : 15/08/18

Manuscript accepted: / manuscrit accepté : 11/02/19

Mots-clés : vieillissement, sclérose en plaques, vieillissement chez soi, incapacité

Keywords: aging, multiple sclerosis, aging in place, disability

La correspondance et les demandes de tirés-à-part doivent être adressées à : / Correspondence and requests for offprints should be sent to:

Michelle Ploughman, Ph.D.

Recovery \& Performance Laboratory

Faculty of Medicine, Memorial University

Rm 400, 100 Forest Rd.

St. John's NL A1A 1E5

(Michelle.ploughman@med.mun.ca) 
Multiple sclerosis (MS) is an immune-mediated disorder of the central nervous system resulting in progressive, and often unpredictable, sensory, physical, and cognitive impairments (Sadovnick, Ebers, Wilson, \& Paty, 1992). Even in their forties, people with MS begin to display slowed motor coordination, comparable with those 30 or more years their senior without MS (Kirkland et al., 2017). Although MS reduces life expectancy by 6-10 years, the proportion of people with MS in the later stages of life is growing and is predicted to increase in the coming decades (Bronnum-Hansen, Stenager, Hansen, \& Koch-Henriksen, 2006; KochHenriksen, Laursen, Stenager, \& Magyari, 2017; Sadovnick et al., 1992). Older people with MS, like most other seniors, wish to remain in their own homes (Stacom, 2017). Further, older adults with MS in their eighth decade of life (octogenarians with MS), represent an under-studied population about whom there is little information about which factors allow some individuals to remain in the community whereas others require institutional care. Understanding potential protective factors could inform health providers in order to better target appropriate advice and intervention to help older people with neurodegenerative diseases such as MS successfully "age in place".

Aging in place refers to the ability to live in one's own home and community regardless of age, income, or disability, which is strongly favored over institutionalization (Cronin \& Mandich, 2015; Davey, de Joux, Nana, \& Arcus, 2004). Failure to achieve aging in place is significantly predicted by dependence in activities of daily living, depression, impaired cognitive function, difficulties with gait and balance, presence of multiple chronic conditions, and polypharmacy (Stuck et al., 2000). These health concerns are typical among persons with MS, so it is not surprising that severity of physical and cognitive dysfunction are also significant predictors of institutionalization among people with MS (Thorpe et al., 2015). From the person's perspective, social support, financial flexibility, resilience, effective and accessible health care, and healthy lifestyle habits are considered to be critical to successful aging at home among people with MS. Because MS is a progressive neurodegenerative disease, it is presumable that very few MS patients in their 80s would continue to live at home. Those who do are likely special in some way that allows them to successfully age in place.

The health of octogenarians with MS as a distinct group has not been examined; however, they have been included in large study cohorts (Ploughman et al., 2014). In these cohorts, people with MS over the age of 55 exhibit healthier lifestyle habits (diet, exercise, drinking alcohol in moderation and abstaining from smoking) than the general population (Ploughman et al., 2014). It is conceivable that octogenarians with MS living at home possess characteristics that protect them against the risk of institutionalization, such as having a milder form of MS with less physical disability or having a greater degree of social support and financial security. Alternatively, these individuals may in fact be living "on the edge" of institutionalization as a result of factors common in the most advanced stages of MS such as high levels of disability, lack of social resources, cognitive impairment, and symptoms of depression.

The overarching aim of the current study was to provide the first description of health, social, and lifestyle factors affecting octogenarians with MS. We employed a two-faceted approach to analyse this unique group by comparing them with a younger sample of people with MS between the ages of 60 and 70 as well as a group of Canadian octogenarians without MS. We hypothesized that octogenarians with MS would have greater disability than their comparators, potentially influencing participation, but would also exhibit protective factors such as high levels of social support, financial stability, and positive lifestyle choices including better diet and exercise practices.

\section{Methods}

\section{Participants and Survey Variables}

We used the Canadian Survey of Health, Lifestyle, and Aging with Multiple Sclerosis (CSHLA-MS) (Ploughman et al., 2014) to create two MS groups: Octogenarians with MS (80-89 years of age) and a younger group referred to as the "young-old MS group" (60-70 years of age). The CSHLA-MS was a self-report postal survey grounded by qualitative research regarding healthy aging with MS (Ploughman, Austin, Stefanelli, \& Godwin, 2010; Ploughman et al., 2012a, 2012b). With the assistance of national MS clinics, MS Society chapters, and newspaper advertisements, participants were recruited if they were 55 years of age or older and had had a diagnosis of MS confirmed by a neurologist with MS symptoms for 20 years or more. In total, 921 individuals were contacted, with 743 participants completing and returning the survey. To compare octogenarians with MS with the young-old MS group, we matched each octogenarian with MS randomly to three younger individuals with MS using the following criteria: (1) being between the ages of 60 and 70, and (2) same gender (M/F), (3) similar total years of education ( \pm 2 years), and (4) from the same province. To obtain a comparison group of octogenarians without MS, we used the 2012 Canadian Community Health Survey (CCHS). We compared octogenarians with MS with participants from the 2012 version of the CCHS who were older than 80 years (Canadian octogenarians). Questions from the CCHS were matched by two members of the research team (M.B.D. and E.M.W.) to 
questions from the CSHLA-MS. As per Ploughman et al. (2014), the data were extracted through online access using the University of Toronto Data Library service, and were analysed using the Survey Documentation and Analysis software

We compared the three groups (octogenarians with MS, the young-old MS group, and Canadian octogenarians) on four main categories of variables: socio-demographics, health and disability, lifestyle, and participation. With respect to the CSHLA-MS survey, questions were either specifically designed for the survey (including visual analogue scales [VAS]) or were obtained from one of the following sources: the Multiple Sclerosis Impact Scale (MSIS-29) (Hobart, Lamping, Fitzpatrick, Riazi, \& Thompson, 2001), the Barthel Index (Mahoney \& Barthel, 1965), the Co-Morbidity Questionnaire (Marrie \& Horwitz, 2010), Frenchay Activities Index (FAI), the Simple Lifestyle Indicator Questionnaire (SLIQ) (Godwin, Pike, \& Bethune, 2013), the Hospital Anxiety and Depression Scale (HADS) (Honarmand \& Feinstein, 2009), the 12-item Resilience Scale (RS-12) (Wagnild \& Young, 1993), and the Personal Resource Questionnaire (PRQ-2000) (Weinert, 1987).

\section{Data and Statistical Analysis}

CSHLA-MS data were entered into SPSS (v.21) for analysis. One way analyses of variance (ANOVAs) were used to compare responses on continuous variables, and $\chi^{2}$ tests were performed on categorical variables. Weighted averages in the form of percentages were used to compare the data from CSHLA-MS (MS groups) and the CCHS (Canadian octogenarians).

\section{Results}

\section{Demographic Characteristics}

There were 23 octogenarians with MS, representing 3.1 per cent of the original CSHLA-MS sample (Table 1). As expected, the octogenarians with MS were significantly older, by about 17 years, than the young-old MS group (mean, 64.6 years [SD $=4.2]$ ). There were no differences in $\operatorname{sex}\left(\chi^{2}=.75, p>.05\right)$ or level of education $\left(\chi^{2}\right.$ $=2.14, p>.05$ ) between the two MS groups. In terms of the use of disease-modifying drugs, only one of the MS octogenarians reported currently being prescribed disease-modifying drugs compared with 17 of the young-old MS group. In keeping with prior research on MS (Harbo, Gold, \& Tintore, 2013), sex distribution favored females in the MS groups but was more evenly split among Canadian octogenarians (octogenarians with MS were $78.3 \%$ female and Canadian octogenarians were $58 \%$ female). Octogenarians with MS reported more formal education than Canadian octogenarians, with only 8.7 per cent having less than a high school education compared with 43.4 per cent of Canadian octogenarians (Table 1).

\section{Socioeconomics}

Despite having been diagnosed with MS a decade earlier, octogenarians with MS reported a slightly higher degree of social support and financial flexibility (although not significantly so) compared with the young-old MS group (Table 2). Concerning living situation, more octogenarians with MS reported living with a partner than did their younger counterparts with MS. Forty-seven per cent of both MS groups reported having private health insurance. Octogenarians with MS reported having to discontinue their employment because of MS half as often as the young-old MS group (Table 2). Socioeconomic data were not available for the Canadian octogenarians sample.

\section{Health and Disability}

The majority of both octogenarians with MS and the young-old group were initially diagnosed with the relapsing remitting form of MS (Table 2). There were no differences in the physical and psychological impacts of MS or in the level of disability measured by the

Table 1: Demographic characteristics

\begin{tabular}{|c|c|c|c|}
\hline Characteristic & $\begin{array}{l}\text { Octogenarians with MS } \\
\qquad \begin{array}{c}n=23 \\
\text { Mean } \pm \text { SD }(\%)\end{array}\end{array}$ & $\begin{array}{l}\text { Young-Old with MS } \\
\qquad n=61 \\
\text { Mean } \pm \text { SD (\%) }\end{array}$ & $\begin{array}{c}\text { Canadian Octogenarians } \\
\qquad n=1,093,230(\%)\end{array}$ \\
\hline Age & $81.9 \pm 2.9(80.7-83.2,95 \% \mathrm{Cl})$ & $* 64.6 \pm 4.2(63.6-65.7,95 \% \mathrm{Cl})$ & $11.4 \%>80$ \\
\hline Sex $M / F$ & $5 / 18(21.7 \% / 78.3 \%)$ & $15 / 46(24.6 \% / 75.4 \%)$ & $459,045 / 634,185$ (42\%/58\%) \\
\hline \multicolumn{4}{|l|}{ Education } \\
\hline Less than high school & $2(8.7 \%)$ & $12(19.7 \%)$ & $442,998(43.4 \%)$ \\
\hline High school & $6(26.1 \%)$ & $15(24.6 \%)$ & 167,703 (16.4\%) \\
\hline 1-2 Year post-graduate & $4(17.4 \%)$ & $13(21.3 \%)$ & $38,208(3.7 \%)$ \\
\hline Complete post-graduate & $11(47.8 \%)$ & $21(34.4 \%)$ & $371,542(36.4 \%)$ \\
\hline
\end{tabular}

Note. $F=332.56, p<.05$.

MS = multiple sclerosis. 
Table 2: Comparing health and lifestyle factors in octogenarians with MS the young-old with MS

\begin{tabular}{|c|c|c|c|}
\hline Description & $\begin{array}{c}\text { Octogenarians with MS } n=23 \\
\text { Mean } \pm \text { SD }(95 \% \mathrm{CI})\end{array}$ & $\begin{array}{c}\text { Young-Old with MS } n=61 \\
\text { Mean } \pm \text { SD }(95 \% \mathrm{CI})\end{array}$ & $\begin{array}{l}\text { Statistical } \\
\text { Comparison }\end{array}$ \\
\hline \multicolumn{4}{|l|}{ Health and disability } \\
\hline MS diagnosis type & & & $\chi^{2}=1.70$ \\
\hline Relapsing remitting & $43.5 \%$ & $50.8 \%$ & \\
\hline Primary or secondary progressive & $21.7 \%$ & $19.7 \%$ & \\
\hline Use of disease-modifying drugs & $4.3 \%$ & $27.9 \%$ & $\chi^{2}=5.49^{*}$ \\
\hline Physical impact of MS (MSIS-29) & $54.5 \pm 14.1(48.4-60.6)$ & $57.4 \pm 20.0(52.2-62.5)$ & $F=0.39$ \\
\hline Psychological impact of MS (MSIS-29) & $18.1 \pm 6.1(15.4-20.7)$ & $21.5 \pm 7.7(19.6-23.5)$ & $F=3.71$ \\
\hline $\begin{array}{l}\text { Disability (Barthel Index, total dependency, 0; } \\
\quad \text { total independence, 100) }\end{array}$ & $68.9 \pm 23.6(58.7-79.1)$ & $75.7 \pm 27.8(68.6-82.8)$ & $F=1.09$ \\
\hline $\begin{array}{l}\text { Moderate to extreme problems with balance } \\
\text { (from MSIS-29) }\end{array}$ & $77.2 \%$ & $72.2 \%$ & $\chi^{2}=0.20$ \\
\hline Depressive symptoms (HADS 0-21) & $5.3 \pm 2.6(4.2-6.5)$ & $6.3 \pm 3.9(5.3-7.3)$ & $F=1.29$ \\
\hline Anxiety symptoms (HADS 0-21) & $5.2 \pm 3.6(3.7-6.7)$ & $6.3 \pm 4.2(5.2-7.4)$ & $F=1.26$ \\
\hline Fatigue today (VAS $0-100 \mathrm{~mm}$ ) & $49.8 \pm 27.0(38.2-61.5)$ & $64.1 \pm 27.8(56.9-71.3)$ & $F=4.48^{*}$ \\
\hline Resilience (RS-12, 12-84) & $80.3 \pm 12.2(75.0-85.6)$ & $74.2 \pm 14.1(70.6-77.8)$ & $F=3.38$ \\
\hline Stress (SLIQ, high 1- low 6) & $4.8 \pm 0.8(4.4-5.1)$ & $3.9 \pm 1.2(3.65-4.26)$ & $F=9.40^{*}$ \\
\hline \multicolumn{4}{|l|}{ Lifestyle } \\
\hline Physical activity (SLIQ, 0-15) & $5.6 \pm 1.8(4.9-6.4)$ & $5.4 \pm 1.7(5.0-5.9)$ & $F=0.19$ \\
\hline $\operatorname{Diet}(S L I Q, 0-15)$ & $9.0 \pm 2.8(7.8-10.2)$ & $9.7 \pm 3.1(8.9-10.5)$ & $F=0.96$ \\
\hline Alcohol use (SLIQ, drinks per week) & $2.6 \pm 5.6(0.13-5.0)$ & $1.7 \pm 3.0(0.9-2.4)$ & $F=0.89$ \\
\hline Smoking status & & & $\chi^{2}=0.21$ \\
\hline Smoker & $0.0 \%$ & $7.0 \%$ & \\
\hline Non-smoker & $100.0 \%$ & $93.0 \%$ & \\
\hline Enough money & $69.6 \%$ & $65.5 \%$ & \\
\hline Not enough money & $13.0 \%$ & $28.0 \%$ & \\
\hline Live with a partner & $47.8 \%$ & $24.6 \%$ & $\chi^{2}=4.22 *$ \\
\hline Have private health insurance & $47.8 \%$ & $47.5 \%$ & $\chi^{2}=0.00$ \\
\hline Stopped working or retired because of MS & $43 \%$ & $79 \%$ & $\chi^{2}=9.69^{*}$ \\
\hline Type of home & & & $\chi^{2}=0.431$ \\
\hline 1. House/apartment/condo & $95.7 \%$ & $95.1 \%$ & \\
\hline 2. Assisted living & $4.3 \%$ & $3.2 \%$ & \\
\hline 3. Long-term care & $0.0 \%$ & $1.6 \%$ & \\
\hline Location & & & $\chi^{2}=0.500$ \\
\hline Rural & $13.0 \%$ & $19.7 \%$ & \\
\hline Urban & $87.0 \%$ & $80.3 \%$ & \\
\hline
\end{tabular}

Note. ${ }^{*} p<0.05$.

MS = multiple sclerosis , $\mathrm{Cl}=$ confidence interval, MSIS-29 = Multiple Sclerosis Impact Scale, HADS = Hospital Anxiety and Depression Scale, VAS = visual analogue scale, RS-12 = Resilience Scale-12, SLIQ = Simple Lifestyle Indicator Questionnaire, FAI = Frenchay Activities Index, PRQ-2000 = Personal Resource Questionnaire.

Barthel Index (Figure 1). The average Barthel Index scores suggested that most respondents in both groups required assistance with at least some activities of daily living. With respect to mental health, both groups had low levels of anxiety and depressive symptoms as measured by the HADS. The octogenarians with MS reported significantly less stress and less fatigue than the young-old group and reported higher levels of 


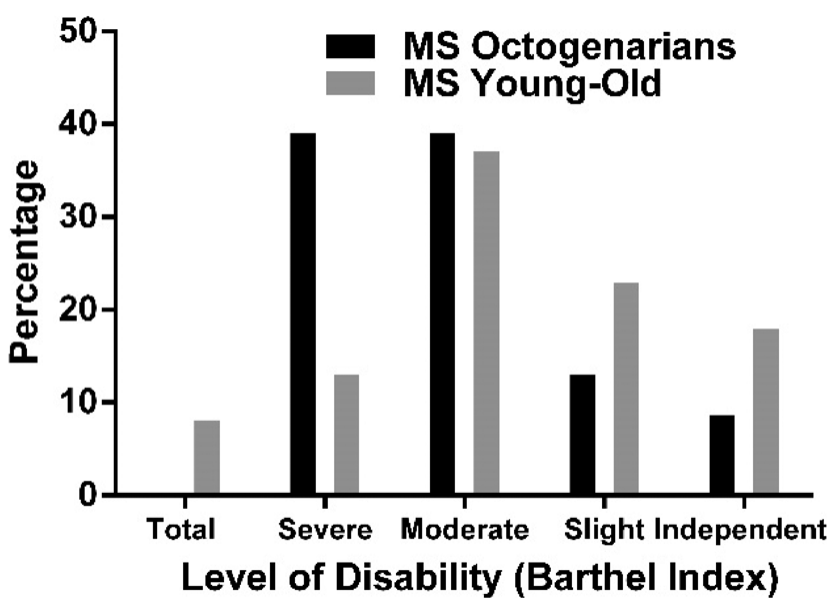

Figure 1: Level of disability measured using the Barthel Index in the octogenarians with multiple sclerosis (MS) and youngold MS groups. Total Dependence is denoted as a total score of 0-20, Severe Dependence is denoted as a total score of 21-60, Moderate Dependence is denoted as a total score of 61-90, Slight Dependence is denoted as a total score of 91-99, and Independent is denoted as a total score of 100, indicating ability to ascend/descend stairs on one's own and perform activities of daily living without assistance

resilience (although not significantly so). Both groups scored on average in the highest quartile on the Resilience Scale. There were no differences between groups concerning mental or musculoskeletal co-morbidities, however octogenarians with MS reported double the number of cardiovascular co-morbidities.

When comparing the health of octogenarians with MS with that of the Canadian octogenarians (Table 3), octogenarians with MS indicated that they required home or personal care services twice as frequently as other Canadians their age. With respect to mobility, less than half of the octogenarians with MS reported being able to walk independently compared with almost 70 per cent of Canadian octogenarians. Octogenarians with MS reported a higher percentage of mental health and cancer-related comorbidities whereas the Canadian octogenarians more often reported arthritis.

\section{Lifestyle}

We compared scores on the Simple Lifestyle Indicator Questionnaire, which tabulated information about physical activity, diet, alcohol intake, and smoking between the MS groups (Godwin et al., 2008). Both groups reported low to moderate levels of physical activity, a good quality diet, and modest alcohol intake, with no differences between groups. Seven per cent of the young-old MS group were smokers compared with none of the MS octogenarians, although smoking habits were not significantly different between groups (Table 2).
When comparing the octogenarian groups (Table 3), 87 per cent of the MS group reported being physically active compared with only a third of Canadian octogenarians. Seventy-eight per cent of octogenarians with MS walked four or more times per week, compared with 58.5 per cent of Canadian octogenarians (Table 3). With respect to diet, the MS group did not appear to choose fruits and vegetables as often as other Canadians of the same age (Table 3). Of Canadian octogenarians, 69.6 per cent reported vegetable consumption in the form of garden salads more than twice weekly, compared with only 21.7 per cent of octogenarians with MS. The MS group also reported 13 per cent less fruit intake two or more times a week. Finally, the groups did not differ greatly with respect to smoking or alcohol consumption.

\section{Participation}

Both the octogenarians with MS and the young-old MS group reported a high degree of household, leisure and out-of-home participation that was not significantly different between groups (Table 2). Octogenarians with MS reported significantly less stress in their lives than the young-old MS respondents (Table 2). More than half of the Canadian and MS octogenarians considered that their chronic health conditions had little or no impact on their participation and ability to function at home (Table 3).

\section{Discussion}

Previous research examining successful aging among the general population has identified four key contributors to healthy aging: social connectedness, physical health, intact psycho-cognitive function, and positive lifestyle behaviours (Gray \& Arnett, 2014; Peel, Bartlett, \& McClure, 2004). For those living and aging with MS, these contributors to successful aging are often threatened by the progressive nature of the disease itself. We undertook this study to determine potentially protective characteristics within a group of older adults living with MS (octogenarians with MS) who continued to live at home. We compared them with a younger group of older adults with MS 60-70 years of age as well as with members of a national sample of octogenarians in Canada. We expected that octogenarians with MS, who were able to successfully remain at home, would have a milder form of the disease and therefore less disability; however this was not the case. Despite similar levels of disability and a greater number of co-morbid conditions, MS octogenarians reported stable and even slightly higher levels of social support and financial security than their younger counterparts. They maintained moderate levels of physical activity and a high degree of household, leisure, and out-ofhome participation despite being more disabled than other Canadians their age. Importantly, they reported significantly less stress and fatigue compared with the 
Table 3: Comparing health and lifestyle factors among octogenarians with and without MS

\begin{tabular}{|c|c|c|}
\hline Description & $\begin{array}{l}\text { Octogenarians with } \\
\text { MS } n=23 n(\%)\end{array}$ & $\begin{array}{l}\text { Canadian Octogenarians } \\
\qquad n=1,075,637 n(\%)\end{array}$ \\
\hline $\begin{array}{l}\text { Health } \\
\text { Perceive life as very stressful ( } 5 \text { or } 6 / 6 \text { ) }\end{array}$ & $7(30.4 \%)$ & $113,786(10.6 \%)$ \\
\hline $\begin{array}{l}\text { Co-morbidities } \\
\text { High blood pressure } \\
\text { Arthritis } \\
\text { Heart disease } \\
\text { Diabetes } \\
\text { Mood disorders } \\
\text { Cancer }\end{array}$ & $\begin{array}{l}14(60.9 \%) \\
5(21.7 \%) \\
7(30.4 \%) \\
3(13.0 \%) \\
5(21.7 \%) \\
7(30.4 \%)\end{array}$ & $\begin{array}{c}550,846(50.9 \%) \\
\mathbf{5 4 4 , 2 9 2}(\mathbf{5 0 . 2} \%) \\
267,763(24.8 \%) \\
187,232(17.1 \%) \\
\mathbf{5 8 , 7 1 7}(\mathbf{5 . 4 \% )} \\
\mathbf{1 0 3 , 3 5 5}(\mathbf{9 . 5} \%)\end{array}$ \\
\hline $\begin{array}{l}\text { Home/personal care services } \\
\text { None } \\
\text { Housekeeping services } \\
\text { Visits for personal care assistance } \\
\text { Personal care in home/facility }\end{array}$ & $\begin{array}{c}34.8 \% \\
47.8 \% \\
26.1 \% \\
34.8 \%\end{array}$ & $\begin{array}{c}372,276(84.0 \%) \\
\text { N/A } \\
\text { N/A } \\
\text { N/A }\end{array}$ \\
\hline $\begin{array}{l}\text { Mobility } \\
\text { Walk independently (with or without a walking aid) } \\
\text { Uses wheelchair } \\
\text { Unable to move }\end{array}$ & $\begin{array}{l}11(47.8 \%) \\
6(26.1 \%) \\
3(13.0 \%)\end{array}$ & $\begin{array}{l}31,498(69.7 \%) \\
\mathrm{N} / \mathrm{A} \\
3,976(8.8 \%)\end{array}$ \\
\hline $\begin{array}{l}\text { How much does your chronic illness (MS; or other in CC } \\
\text { Little to never } \\
\text { Moderately } \\
\text { Consistently }\end{array}$ & $\begin{array}{l}\text { ur ability to participate in } \\
\qquad \begin{array}{c}12(52.2 \%) \\
7(30.4 \%) \\
4(17.4 \%)\end{array}\end{array}$ & $\begin{array}{l}562,299(51.8 \%) \\
239,958(22.1 \%) \\
283,379(26.1 \%)\end{array}$ \\
\hline $\begin{array}{l}\text { Lifestyle } \\
\text { Participate in some physical activity }\end{array}$ & $20(87.0 \%)$ & $295,867(30.9 \%)$ \\
\hline $\begin{array}{l}\text { How many times do you eat fruit per week? } \\
\quad \leq 1 \\
\geq 2\end{array}$ & $\begin{array}{l}5(21.7 \%) \\
18(78.3 \%)\end{array}$ & $\begin{array}{c}76,222(8 \%) \\
834,703(91.5 \%)\end{array}$ \\
\hline $\begin{array}{l}\text { Smoking status } \\
\text { Smoker } \\
\text { Non-Smoker } \\
\text { Alcohol consumption in the past week }\end{array}$ & $\begin{array}{c}\mathbf{0 . 0} \% \\
100.0 \% \\
11(47.8 \%)\end{array}$ & $\begin{array}{c}\mathbf{5 6 , 2 4 2}(\mathbf{5 . 2} \%) \\
1,022,937(94.6 \%) \\
262,752(54.5 \%)\end{array}$ \\
\hline
\end{tabular}

Note. Bold type emphasis indicates variables that are substantially different between groups.

MS = multiple sclerosis, CCHS = 2012 Canadian Community Health Survey.

young-old MS group. Our findings support that there are five interrelated elements contributing to successful aging among the very oldest people with MS: social support, financial security, attitude, positive lifestyle behaviours (particularly exercise), and participation in life roles. These five factors overlap with some of the elements described in previous qualitative and quantitative studies examining healthy aging with MS, suggesting that these five elements move to higher priority among the oldest old living with MS (Ploughman et al., 2012a; Wallack, Wiseman, \& Ploughman, 2016).

Our results confirm that social support is central to successful aging in place among people with MS (Foote, Piazza, Holcombe, Paul, \& Daffin, 1990; Ploughman et al., 2012a; Wallack et al., 2016; Wineman, 1990). The PRQ-2000 survey employed in this study not only measured elements of operational support (physical and emotional assistance) but also attachment to others, 
social integration, nurturance, and feelings of worth (Weinert, 2003), so it provided a comprehensive measure of social connectedness. The scores on the PRQ-2000 in this sample of octogenarians with MS were very high with a mean score of 88.6 out of 105 (10 points higher than the young-old group with MS), suggesting that the octogenarians with MS were socially connected within their families and communities and received assistance as needed. Their average score was higher than that reported among older community-dwelling individuals who scored between 80 and 85 (Tawalbeh \& Ahmad, 2013), and higher than those measured among older persons with type 2 diabetes whose scores averaged 80/105 (Bai, Chiou, \& Chang, 2009; Bai, Chiou, Chang, \& Lam, 2008). Further, the octogenarians with MS average PRQ2000 score exceeded those reported from large samples of younger people with MS $(n=499, n=450)$ whose average scores were 82 and 85 (Weinert, 2003). Clearly, social support and connectedness should be emphasized by health teams in order to foster aging in place.

The exceptionally high degree of social connectedness in the octogenarians with MS suggests that they were also successful in maintaining co-habitation and marriage. Our data support that, along with high PRQ2000 scores, they were more likely to live with their partner than were the MS young-old group. This fact is important, because people aging with MS are at great risk of divorce. Pfleger and group reported that the risk of divorce or separation was higher among people with MS (12\%) and that risk worsened over 24 years (to $67 \%$ ) compared with controls (47\%) (Pfleger, Flachs, \& Koch-Henriksen, 2010). Among people with dementia, being single carried eight times greater risk of institutionalization compared with being married (Luppa et al., 2010). Along with the social support provided with marriage, there is likely greater financial security with a potential second income and savings. Our data confirmed that 87 per cent of octogenarians with MS reported that they had enough, or more than enough money to meet their needs. Such security is important, because the estimated out of pocket cost of MS in Canada was $\$ 16,800$ in 2011 and was predicted to rise in the future (Nana et al., 2017). Financial stability, and its inter-relationships with social support and public health, seems to be important to aging in place when living with a chronic disease such as MS. Future research should examine the impact of finances and public health systems on aging in place, particularly comparing practices in other countries.

Despite requiring assistance to perform activities of daily living, octogenarians with MS reported a high degree of participation in household, leisure, and outof-home activities, similar to levels reported by people with MS who were 10 years their junior. They were also more physically active than other Canadians their age despite reporting greater disability. Notably, over half of respondents in the octogenarians with MS group reported that their chronic condition had little to no impact on their ability to participate. In this unique group of the oldest-old living at home with a neurodegenerative condition, protective factors such as social support and financial stability may foster participation and buffer the deleterious effects of having mobility impairments. For example, 66 per cent of octogenarians with MS reported that they received outside assistance for housekeeping and personal care compared with only 16 per cent of Canadian octogenarians. Such physical care, and the finances to provide such support (because in Canada most services are not covered by the government plan), likely permits octogenarians with MS to successfully age in place. Furthermore, 47 per cent of both MS groups reported having private health insurance, higher than previously reported for Ontario senior citizens (27\%) (Allin, Law, \& Laporte, 2013). It is reasonable to think that people with MS should receive counselling early in the disease to establish financial security, as it likely contributes to the ability to afford private health insurance and to obtain paid personal care, factors that synergistically facilitate aging in place.

We found that fewer of the octogenarians with MS in our sample retired or stopped working because of MS $(43 \%)$ compared with their younger counterparts (79\%). Paid work often provides purpose, development of social networks, and financial stability. Work is especially valued among people with MS who express that the non-financial benefits of work are as important as the financial ones (Robinson, 1993). The present findings may suggest that the ability to continue to work while living with MS enhances the capacity to age in place; however, it is worth noting that generational differences between octogenarians with MS and the young-old group may play a role in this difference. From a historical perspective, older generations tended to have women work at home more frequently than more recent generations (Ferrao, 2010). As most (78.3\%) of the octogenarians with MS in our sample were female, it is conceivable that some of these respondents did not work outside of the home and so may have indicated that they had not retired (from presumably paid work). Nevertheless, it is concerning that 79 per cent of the young-old MS group indicated that they had to retire or stop working because of MS. This forced retirement or unemployment can place these individuals at great risk of financial destabilization and social isolation. It was interesting to note that the octogenarians with MS were highly educated, with almost 48 per cent having completed post-graduate education, more than 10 percentage points higher than the young-old and Canadian octogenarians groups. It is also possible that, because of their level of advanced education, 
the octogenarians with MS were able to continue paid work longer because their work may not have required extensive physical demands. Level of education on its own can be protective. For example, among older people receiving Medicare in the United States, having less than a high school diploma increased odds of deterioration, institutionalization, or death by 24 per cent (Kurichi et al., 2017). Furthermore, level of education, advanced occupational attainment, and participation in leisure activities may help to build "cognitive reserve" (Stern, 2012) thereby providing some protection against neurodegeneration. Whether unemployment hastens cognitive decline or shrinking of the "cognitive reserve" is not clear; however, work modifications and other methods to maintain employment as mediators of aging in place are worthy of future investigation.

More than 70 per cent of older people with MS report moderate to extreme balance problems (Ploughman, Deshpande, Latimer-Cheung, \& Finlayson, 2014) and falls and fear of falling threaten independent living among people aging with a disability (Finlayson \& Peterson, 2010; Ploughman et al., 2014). When compared with age-matched controls, Einarsson, Gottberg, Fredrikson, von Koch, \& Holmqvist (2006) found that people with MS (mean age $51 \pm 12$ ) performed only 35 per cent of the social and lifestyle activities that their peers did (Einarsson et al., 2006). Our findings suggest that despite having a greater number of co-morbid conditions, moderate to severe levels of disability $(80 \%)$ and balance problems, octogenarians with MS participated in valued activities at similar levels as people living with MS who were 17 years their junior, as well as at similar levels as their peers of the same age living without MS. Although we did not examine falls or fear of falling, it seems as though octogenarians with MS are able to overcome the challenges associated with level of disability, higher number of co-morbid conditions, and poor balance in order to maintain exercise levels and household, leisure and out of home activities (Ploughman, 2017; Ploughman et al., 2015). This result suggests that there is sound rationale for including behavioural therapies that help manage the barriers associated with aging with a chronic disease in a care plan to help people age in place.

Psychological factors such as mood, attitude, and levels of resilience and fatigue likely contribute to participation and to perceived quality of life. Octogenarians with MS reported low levels of depression and anxiety and high levels of resilience and had significantly lower levels of stress and fatigue than the young-old group of people with MS. However, they also had a higher overall prevalence of mood disorders than Canadians their age. High levels of fatigue and low levels of physical activity are part of a vicious cycle, in which one perpetuates the other (Ploughman, 2017) and attitude is second only to level of disability as a major barrier to participation in physical activity for people with MS (Ploughman, 2017). There is a large body of evidence to suggest that both anxiety and depression are more common among people with MS than among the general population (Boeschoten et al., 2017). Among 7,757 respondents $65-103$ years of age living in 16 European countries, there was a reciprocal relationship between participation in physical activity and positive attitude, despite mobility challenges (Lee, 2016) suggesting that psychological health and physical activity are linked. Our results, along with those of others, support that management of depression, anxiety, stress, and fatigue are important for fostering participation in life roles, physical activity, and successful aging with MS.

Our study offers the first description of the prevalence of health and lifestyle factors of octogenarians with MS. However, there are several limitations to the present study. First, the data were derived from self-report and are therefore subjective, and could be subject to recall bias. Second, we were only able to use the CCHS data as reference values, so we were unable to statistically compare the Canadian octogenarians with octogenarians with MS. Because completing questionnaires requires intact cognitive abilities, we were unable to discern whether there were differences in cognition between the groups. Cognitive impairment places older people at greater risk of institutionalization (Thorpe et al., 2015), so future studies should examine cognition and institutionalization among older people with MS. The cross-sectional study design is limited in that it cannot infer changes that occur as the same individuals age across time. Future work should address this issue by conducting longitudinal research examining changes in health and lifestyle factors among older people with MS to more closely examine how those aging with MS change across the lifespan. Further, only a small fraction of the CSHLA-MS respondents $(n=23)$ were octogenarians, possibly representing a small portion of survivors. There is likely sampling bias because people who participate in surveys are more likely to have post-secondary education and are less likely to be from disadvantaged groups (Voigt, Koepsell, \& Daling, 2003). Survey respondents also tend to be healthier overall (Keyes, Rutherford, Popham, Martins, \& Gray, 2018). The small sample and potential sampling bias limits generalizability. When comparing with the Canadian cohort, the sample of MS is only 23 compared with more than 1,000,000 respondents in the national survey. Lastly, we could only compare questions from the CSHLA-MS with questions from the CCHS that matched, and in some cases wording was not exactly the same.

\section{Conclusion}

Our study offers the first description of the prevalence of health and lifestyle factors in a population of octogenarians with MS. Importantly, five elements including social 
support, financial security, attitude, positive lifestyle behaviours (particularly exercise), and participation in life roles appear to be integral to aging in place among the very oldest people with MS. When compared with previous work in the field of healthy aging with MS, we suggest that these five elements take on high priority among the oldest old living with MS. Accordingly, these factors should be considered as important targets for early intervention to support young and middle-aged individuals with MS who intend to plan for aging in place.

\section{References}

Allin, S., Law, M. R., \& Laporte, A. (2013). How does complementary private prescription drug insurance coverage affect seniors' use of publicly funded medications? Health Policy, 110(2-3), 147-155. doi: 10.1016/j.healthpol.2013.02.010

Bai, Y. L., Chiou, C. P., \& Chang, Y. Y. (2009). Self-care behaviour and related factors in older people with type 2 diabetes. Journal of Clinical Nursing, 18(23), 3308-3315. doi: 10.1111/j.1365-2702.2009.02992.x

Bai, Y. L., Chiou, C. P., Chang, Y. Y., \& Lam, H. C. (2008). Correlates of depression in type 2 diabetic elderly patients: A correlational study. International Journal of Nursing Studies, 45(4), 571-579. doi: 10.1016/j.ijnurstu.2006.07.026

Boeschoten, R. E., Braamse, A. M. J., Beekman, A. T. F., Cuijpers, P., van Oppen, P., Dekker, J., et al (2017). Prevalence of depression and anxiety in multiple sclerosis: A systematic review and meta-analysis. Journal of the Neurological Sciences, 372, 331-341. doi: 10.1016/j.jns.2016.11.067

Bronnum-Hansen, H., Stenager, E., Hansen, T., \& KochHenriksen, H. (2006). Survival and mortality rates among Danes with MS. International MS Journal, 13(2), 66-71.

Cronin, A., \& Mandich, M. B. (2015). Human development and performance throughout the lifespan: Boston: Cengage Learning..

Davey, J. A., de Joux, V., Nana, G., \& Arcus, M. (2004). Accommodation options for older people in Aotearoa/New Zealand: Christchurch: Centre for Housing Research Christchurch.

Einarsson, U., Gottberg, K., Fredrikson, S., von Koch, L., \& Holmqvist, L. W. (2006). Activities of daily living and social activities in people with multiple sclerosis in Stockholm County. Clinical Rehabilitation, 20(6), 543-551. doi: 10.1191/0269215506cr953oa

Ferrao, V. (2010). Paid work. Women in Canada: A gender-based statistical report (6th ed.). Retrieved 19 December 2018 from https: / /www150.statcan.gc.ca/n1/en/pub/89503-x/89-503-x2010001-eng.pdf?st=5dpxnvQ1.

Finlayson, M. L., \& Peterson, E. W. (2010). Falls, aging, and disability. Physical Medicine and Rehabilitation Clinics of North America, 21(2), 357-373. doi: 10.1016/j.pmr.2009.12.003

Foote, A. W., Piazza, D., Holcombe, J., Paul, P., \& Daffin, P. (1990). Hope, self-esteem and social support in persons with multiple sclerosis. The Journal of Neuroscience Nursing, 22(3), 155-159.
Godwin, M., Pike, A., \& Bethune, C. (2013). Concurrent and convergent validity of the simple lifestyle indicator questionnaire. ISRN Family Medicine, 2013, 529645. doi: $10.5402 / 2013 / 529645$

Godwin, M., Streight, S., Dyachuk, E., van den Hooven, E. C., Ploemacher, J., Seguin, R., et al (2008). Testing the simple lifestyle indicator questionnaire: Initial psychometric study. Canandian Family Physician, 54(1), 76-77.

Gray, V., \& Arnett, P. (2014). Aging with multiple sclerosis: Cognitive, emotional and neuropathological considerations. Neurodegenerative Disease Management, 4(2), 187-194. doi: $10.2217 /$ nmt.14.12

Harbo,H.F., Gold, R., \& Tintore, M. (2013).Sexand gender issues in multiple sclerosis. Therapeutic Advances in Neurological Disorders, 6(4), 237-248. doi: 10.1177/1756285613488434

Hobart, J., Lamping, D., Fitzpatrick, R., Riazi, A., \& Thompson, A. (2001). The Multiple Sclerosis Impact Scale (MSIS-29): A new patient-based outcome measure. Brain, 124(Pt 5), 962-973.

Honarmand, K., \& Feinstein, A. (2009). Validation of the Hospital Anxiety and Depression Scale for use with multiple sclerosis patients. Multiple Sclerosis, 15(12), 1518-1524. doi: 10.1177/1352458509347150

Keyes, K.M., Rutherford,C.,Popham,F., Martins, S.S., \& Gray, L. (2018). How healthy are survey respondents compared with the general population? Using survey-linked death records to compare mortality outcomes. Epidemiology, 29(2), 299-307. doi: 10.1097/EDE.0000000000000775

Kirkland, M. C., Downer, M. B., Holloway, B. J., Wallack, E. M., Lockyer, E. J., Buckle, N. C. M., et al (2017). Bipedal hopping reveals evidence of advanced neuromuscular aging among people with mild multiple sclerosis. Journal of Motor Behaviour, 49(5), 505-513. doi: 10.1080/00222895.2016.1241750

Koch-Henriksen, N., Laursen, B., Stenager, E., \& Magyari, M. (2017). Excess mortality among patients with multiple sclerosis in Denmark has dropped significantly over the past six decades: A population based study. Journal of Neurology Neurosurgery \& Psychiatry, 88(8), 626-631. doi: 10.1136/jnnp-2017-315907

Kurichi, J. E., Streim, J. E., Xie, D., Hennessy, S., Na, L., Saliba, D., et al (2017). The association between activity limitation stages and admission to facilities providing long-term care among older medicare beneficiaries. American Journal of Physical Medicine \& Rehabilitation, 96(7), 464-472. doi: 10.1097/PHM.0000000000000653

Lee, S. (2016). An exploration of antecedents of positive affect among the elderly: A cross-sectional study. European Journal of Public Health, 26(1), 187-191. doi: 10.1093/eurpub/ckv067

Luppa, M., Luck, T., Weyerer, S., Konig, H. H., Brahler, E., \& Riedel-Heller, S. G. (2010). Prediction of institutionalization in the elderly. A systematic review. Age and Ageing, 39(1), 31-38. doi: 10.1093/ageing/afp202 
Mahoney, F. I., \& Barthel, D. W. (1965). Functional evaluation: The Barthel Index. Maryland State Medical Journal, 14, 61-65.

Marrie, R. A., \& Horwitz, R. I. (2010). Emerging effects of comorbidities on multiple sclerosis. The Lancet Neurology, 9(8), 820-828. doi: 10.1016/s1474-4422(10)70135-6

Nana, A., Ruth, A. M., Christina, B., Rochelle, G., Douglas, G. M., Ron, W., et al (2017). Multiple sclerosis in Canada 2011 to 2031: Results of a microsimulation modelling study of epidemiological and economic impacts. Health Promotion and Chronic Disease Prevention in Canada: Research, Policy and Practice, 37(2), 37-48.

Peel, N., Bartlett, H., \& McClure, R. (2004). Healthy ageing: How is it defined and measured? Australasian Journal on Ageing, 23(3), 115-119. doi: 10.1111/j.1741-6612.2004.00035.x

Pfleger, C. C., Flachs, E. M., \& Koch-Henriksen, N. (2010). Social consequences of multiple sclerosis. Part 2. Divorce and separation: A historical prospective cohort study. Multiple Sclerosis Journal, 16(7), 878-882. doi: 10.1177/1352458510370978

Ploughman, M. (2017). Breaking down the barriers to physical activity among people with multiple sclerosis-A narrative review. Physical Therapy Reviews, 22(3-4), 124-132. doi: 10.1080/10833196.2017.1315212

Ploughman, M., Austin, M., Stefanelli, M., \& Godwin, M. (2010). Applying cognitive debriefing to pre-test patientreported outcomes in older people with multiple sclerosis. Quality of Life Research, 19(4), 483-487. doi: 10.1007/ s11136-010-9602-z

Ploughman, M., Austin, M. W., Murdoch, M., Kearney, A., Fisk, J. D., Godwin, M., et al (2012). Factors influencing healthy aging with multiple sclerosis: A qualitative study. Disability and Rehabilitation, 34(1), 26-33. doi: 10.3109/09638288.2011.585212

Ploughman, M., Austin, M. W., Murdoch, M., Kearney, A., Godwin, M., \& Stefanelli, M. (2012). The path to selfmanagement: A qualitative study involving older people with multiple sclerosis. Physiotherapy Canada, 64(1), 6-17. doi: 10.3138/ptc.2010-42

Ploughman, M., Beaulieu, S., Harris, C., Hogan, S., Manning, O. J., Alderdice, P. W., et al (2014). The Canadian survey of health, lifestyle and ageing with multiple sclerosis: Methodology and initial results. BMJ Open, 4(7), e005718. doi: 10.1136/bmjopen-2014-005718

Ploughman, M., Deshpande, N., Latimer-Cheung, A. E., \& Finlayson, M. (2014). Drawing on related knowledge to advance multiple sclerosis falls-prevention research. International Journal of MS Care, 16(4), 163-170. doi: 10.7224/1537-2073.2014-052

Ploughman, M., Harris, C., Wallack, E. M., Drodge, O., Beaulieu, S., Mayo, N., et al (2015). Predictors of exercise participation in ambulatory and non-ambulatory older people with multiple sclerosis. PeerJ, 3, e1158. doi: $10.7717 /$ peerj. 1158

Robinson, C. A. (1993). Managing life with a chronic condition: The story of normalization. Qualitative Health Research, 3(1), 6-28. doi: 10.1177/104973239300300102

Sadovnick, A. D., Ebers, G. C., Wilson, R. W., \& Paty, D. W. (1992). Life expectancy in patients attending multiple sclerosis clinics. Neurology, 42(5), 991-994. doi: 10.1212/ wnl.42.5.991

Stacom, R. (2017). Goals of care in people living with advanced multiple sclerosis. Paper presented at theAnnual Meeting of the Consortium of Multiple Sclerosis, New Orleans, Louisiana, 25-27 May 2017.

Stern, Y. (2012). Cognitive reserve in ageing and Alzheimer's disease. The Lancet Neurology, 11(11), 1006-1012. doi: 10.1016/S1474-4422(12)70191-6

Stuck, A. E., Minder, C. E., Peter-Wuest, I., Gillmann, G., Egli, C., Kesselring, A., et al (2000). A randomized trial of in-home visits for disability prevention in community-dwelling older people at low and high risk for nursing home admission. Archives of Internal Medicine, 160(7), 977-986.

Tawalbeh, L. I., \& Ahmad, M. M. (2013). Personal resource questionnaire: A systematic review. The Journal of Nursing Research,21(3), 170-177. doi: 10.1097/01.jnr.0000432049. 31921.ab

Thorpe,L.U.,Knox,K.,Jalbert, R.,Hyun-Ja Lim,J.,Nickel,D., \& Hader, W. J. (2015). Predictors of institutionalization for people with multiple sclerosis. Disability and Health Journal, 8(2), 271-277. doi: 10.1016/j.dhjo.2014.10.002

Voigt, L. F., Koepsell, T. D., \& Daling, J. R. (2003). Characteristics of telephone survey respondents according to willingness to participate. American Journal of Epidemiology, 157(1), 66-73.

Wagnild, G. M., \& Young, H. M. (1993). Development and psychometric evaluation of the Resilience Scale. Journal of Nursing Measurement, 1(2), 165-178.

Wallack, E. M., Wiseman, H. D., \& Ploughman, M. (2016). Healthy aging from the perspectives of 683 older people with multiple sclerosis. Multiple Sclerosis International, 2016, 1845720. doi: 10.1155/2016/1845720

Weinert, C. (1987). A social support measure: PRQ85. Nursing Research, 36(5), 273-277.

Weinert, C. (2003). Measuring social support: PRQ2000. In O Strickland \& C Dilorio (Eds.) Measurement of nursing outcomes. Self Care and Coping (Vol. 3) (pp. 161-172). New York: Springer Publishing.

Wineman, N. M. (1990). Adaptation to multiple sclerosis: The role of social support, functional disability, and perceived uncertainty. Nursing Research, 39(5), 294-299. 